\title{
Use of Self-Care and Practitioner-Based Forms of Complementary and Alternative Medicine before and after a Diagnosis of Breast Cancer
}

\author{
Alissa R. Link, ${ }^{1}$ Marilie D. Gammon, ${ }^{2}$ Judith S. Jacobson, ${ }^{1}$ \\ Page Abrahamson, ${ }^{2}$ Patrick T. Bradshaw, ${ }^{3}$ Mary Beth Terry, ${ }^{1}$ Susan Teitelbaum, \\ Alfred Neugut, ${ }^{1,5}$ and Heather Greenlee ${ }^{1,5}$ \\ ${ }^{1}$ Department of Epidemiology, Mailman School of Public Health, Columbia University, 722 West 168th Street, \\ New York, NY 10032, USA \\ ${ }^{2}$ Department of Epidemiology, University of North Carolina, 2101 McGavran-Greenberg Hall, \\ CB No. 7435 Chapel Hill, NC 27599, USA \\ ${ }^{3}$ Department of Nutrition, Department of Epidemiology, University of North Carolina, 2200 McGavran-Greenberg Hall, \\ CB No. 7461 Chapel Hill, NC 27599, USA \\ ${ }^{4}$ Department of Preventive Medicine, Mount Sinai School of Medicine, 17 E 102nd Street, New York, NY 10029, USA \\ ${ }^{5}$ Department of Medicine, College of Physicians and Surgeons, Columbia University, 722 West 168th Street, New York, NY 10032, USA
}

Correspondence should be addressed to Alissa R. Link; alissa.link@gmail.com

Received 17 April 2013; Revised 21 June 2013; Accepted 7 July 2013

Academic Editor: Holger Cramer

Copyright (C) 2013 Alissa R. Link et al. This is an open access article distributed under the Creative Commons Attribution License, which permits unrestricted use, distribution, and reproduction in any medium, provided the original work is properly cited.

Purpose. We examine factors associated with self-care, use of practitioner-based complementary and alternative medicine (CAM), and their timing in a cohort of women with breast cancer. Methods. Study participants were women with breast cancer who participated in the Long Island Breast Cancer Study Project. Self-care is defined as the use of multivitamins, single vitamins, botanicals, other dietary supplements, mind-body practices, special diets, support groups, and prayer. Within each modality, study participants were categorized as continuous users (before and after diagnosis), starters (only after diagnosis), quitters (only before diagnosis), or never users. Multivariable logistic regression was used for the main analyses. Results. Of 764 women who provided complete data, $513(67.2 \%)$ initiated a new form of self-care following breast cancer diagnosis. The most popular modalities were those that are ingestible, and they were commonly used in combination. The strongest predictor of continuous use of one type of self-care was continuous use of other types of self-care. Healthy behaviors, including high fruit/vegetable intake and exercise, were more strongly associated with continuously using self-care than starting self-care after diagnosis. Conclusions. Breast cancer diagnosis was associated with subsequent behavioral changes, and the majority of women undertook new forms of self-care after diagnosis. Few women discontinued use of modalities they used prior to diagnosis.

\section{Introduction}

Over the past two decades, the use of complementary and alternative medicine (CAM) practices-modalities used for health and wellbeing that are considered outside the realm of conventional medicine-has been steadily rising in the United States [1-3]. Patients with cancer and other chronic diseases are more likely to use CAM than are those without chronic illness [4], and breast cancer patients are more likely to use CAM than patients with colon [5], prostate [5], or gynecological [6] cancers. Estimates of CAM use among women with breast cancer range from $48 \%$ to $86 \%$ [7-9].

The frequency of CAM use among breast cancer patients is not surprising in the light of the physical and emotional burden that breast cancer entails. Breast cancer patients report using CAM for recovery, healing, improving health, strengthening the immune system, reducing side effects of cancer treatments, reducing physical and psychological 
distress [10], and increasing feelings of control [10, 11]. CAM encompasses a vast array of modalities, some of which require a CAM practitioner or provider, a commitment of patient and practitioner time, and practitioner payment; only some states in the US mandate health insurance coverage of CAM practitioners. Other modalities fall into the category of self-care, a range of activities in which individuals engage autonomously and regularly to maintain or improve health, beauty, spiritual connection, or general wellbeing.

Due to the fact that large numbers of cancer patients use CAM, it is increasingly important to develop epidemiological methods to both describe and analyze CAM use patterns. Historically, most analyses of CAM use among cancer populations have focused on use after diagnosis. However, it is important to consider postdiagnosis CAM use in context of the patient's behavior prior to a cancer diagnosis. In this paper, we present a novel approach to describe changes in CAM use before and after breast cancer diagnosis. Furthermore, since CAM encompasses a wide variety of individual modalities that have different implications on pathophysiology and treatment course, we propose that it is important to consider changes in CAM use across specific categories of CAM.

Using follow-up data from the Long Island Breast Cancer Study Project, we analyzed predictors of self-care practices and practitioner-based modalities of CAM before and after a first breast cancer diagnosis. Most studies of CAM use do not separate self-care (i.e., modalities that patients can access and use on their own) from practitioner-based modalities. Our primary aim was to analyze the determinants of self-care versus practitioner-based modalities; other aims were to determine how use of these modalities changed after the breast cancer diagnosis and how use of self-care and practitionerbased modalities might be associated with health-related behaviors such as exercise, smoking, and alcohol intake.

\section{Methods}

2.1. Participants. The Long Island Breast Cancer Study Project (LIBCSP) originated as a population-based, casecontrol study of women residing in Nassau or Suffolk county, New York, USA [12]. The LIBCSP was federally mandated to investigate the possibility of associations between environmental toxicants and the high incidence of breast cancer on Long Island. Eligible cases were women diagnosed with first primary in situ or invasive breast cancer between August 1996 and July 1997. Potential cases were identified through frequent communication with pathology departments at every hospital on Long Island, and 3 major tertiary care facilities in New York City. The physicians of potentially eligible women confirmed diagnoses and gave permission to contact eligible cases; $82.1 \%$ of eligible subjects with a consenting physician agreed to participate in the study. The study enrolled 1508 cases [12].

Between 2002 and 2004, a follow-up study was conducted among the LIBCSP cases [13]. Of the 1414 cases (93.8\%) who agreed to future contact, 1098 (77.4\%) participated in the follow-up, but 334 (23.6\%) completed only a short-form interview or had a proxy interview (completed by a relative on their behalf). Only those who completed the full followup telephone interview [14] were included in the analysis reported here.

Institutional review boards at all participating institutions approved the study protocol, and all participants provided written informed consent prior to the in-person baseline interview and verbal consent prior to the telephone followup interview.

\subsection{Data Collection}

2.2.1. Baseline Questionnaire. The baseline questionnaire was administered to cases by a trained interviewer in the respondent's home soon after a first primary breast cancer diagnosis (mean $=89$ days among the subsample with a full followup telephone interview). Women responded to a detailed questionnaire that took on average 100 minutes to complete and covered known and suspected risk factors for breast cancer, including environmental exposures, reproductive and menstrual histories, medical history, and demographic characteristics. Women were also asked about lifestyle and health behaviors across the life course, including cigarette and alcohol use [12] and recreational physical activity using a modification of the instrument developed by Bernstein et al. [15]. Data on usual dietary intake in the year prior to the baseline interview were collected using a self-completed modified Block food frequency questionnaire [16].

2.2.2. Follow-Up Questionnaire. The full-length follow-up questionnaire, which was administered by telephone by a trained interviewer and lasted about 45 minutes, assessed treatment details for the first primary breast cancer diagnosis, factors associated with breast cancer prognosis, postdiagnosis medical history, and health behaviors. The followup interview included detailed questions about CAM used, specifically, before breast cancer diagnosis, after diagnosis, and during breast cancer treatment. The CAM questionnaire covered use of multivitamins, single vitamins, minerals, herbs and botanicals, other dietary supplements, mind-body practices, support groups, prayer and special diets, and visits to CAM practitioners [14]. Table 1 lists the single agents and modalities within each category.

2.2.3. Medical Records. Medical records obtained at the time of baseline and follow-up were used to confirm disease characteristics and treatment course. For case women for whom complete medical records were available $(n=598)$, information abstracted from the records was in excellent agreement ( $\kappa=0.92-0.96)$ with the women's responses to questions about treatment in the follow-up questionnaire; we therefore relied on the follow-up questionnaire data for information about cancer treatment [13].

\subsection{Data Analysis}

2.3.1. Data Categorization. In this analysis, we defined selfcare as use of multivitamins, single vitamins, botanicals, other 
TABLE 1: List of individual modalities within each category of self-care and practitioner-based CAM, reported in the LIBCSP follow-up interview (2002-2004).

\begin{tabular}{|c|c|}
\hline Category & Individual modalities \\
\hline Multivitamins & $\begin{array}{c}\text { Multivitamin with minerals, Multivitamin without minerals, antioxidant } \\
\text { combination type (A, C, E), stress-tabs, women's formula (MV), multivitamin } \\
\text { with Herbs, other multi-vitamin }\end{array}$ \\
\hline Single vitamins & $\begin{array}{l}\text { Vitamin A with beta carotene, vitamin A without beta carotene, beta carotene } \\
\text { (alone), vitamin B1/thiamin, vitamin B3/niacin, vitamin B6, vitamin B12, B } \\
\text { complex vitamins, vitamin C, vitamin D and calcium, vitamin D, vitamin E } \\
\text { (alpha-tocopherol), magnesium, calcium, rolaids, tums, dolomite, folic } \\
\text { acid/folate, selenium, iron, zinc, lutein, chromium }\end{array}$ \\
\hline Botanicals & $\begin{array}{c}\text { Aloe vera, Ashwagandha, Atractylodes, Astragalus root, Bee pollen, Bilberry, Black } \\
\text { cohosh, clue cohosh, blue-green algae, borage seed oil, bromelain, Burdock, } \\
\text { Calendula, Cascara sagrada, cat's claw, chamomile, chaste tree, Vitex, or chaste } \\
\text { berry, cranberry, Dandelion, dong quai, Echinacea, elder, ephedra, essiac or } \\
\text { florEssence, evening primrose oil, Fennel, feverfew, garlic, ginger, Ginkgo biloba, } \\
\text { ginseng, goldenseal, grape seed oil, green tea, hawthorne, horse chestnut, kava } \\
\text { kava, kelp, lavender, maitake mushroom, milk thistle, Nettle, pau d'arco, } \\
\text { proanthocyanidin, pycnogenol, red clover, reishi mushroom, shiitake } \\
\text { mushroom, slippery elm, soy supplements or isoflavones, St. John's Wort, } \\
\text { valerian, wild yam, willow bark }\end{array}$ \\
\hline
\end{tabular}

Other dietary supplements Products

Mind-body

Special diets

Practitioner-based
Fiber supplement, coenzyme Q10 (CoQ10), shark cartilage, melatonin, flax seed oil, fish oil/EPA/Omega-3/cod liver oil, glucosamine, chondroitin, DHEA, acidophilus, arginine, leucine

Meditation, visualization/imagery, tai chi, qi gong, yoga, dance therapy, art therapy, music therapy, poetry therapy or journaling, biofeedback

Vegan diet, vegetarian diet, no red meat, organic fruits and vegetables, macrobiotic diet, low-fat diet, high-fiber diet, changed your consumption of soy products, diet or program designed to lose weight

Massage, water treatment or hydrotherapy, reiki, healing touch, or other energy therapy, bioeletromagnetic therapy, acupuncture, ayurvedic medicine, Chinese medicine, chiropractic therapy, herbalist, homeopathy, native american

Medicine, naturopathic physician, nutritionist or dietician, tibetan, other CAM practitioner, hypnosis, psychotherapy dietary supplements, mind-body practices, prayer, support groups, and use of special diets. We distinguished self-care from visits to CAM practitioners, which usually entail a time commitment, an encounter, and a fee for the services of another individual.

Within each category or type of self-care and practitionerbased CAM, we grouped the women into 4 distinct groups by timing of use in relation to their breast cancer diagnosis: "continuous users" used $\geq 1$ modality within the category both before and after diagnosis; "starters" started using $\geq 1$ modality from within a category after diagnosis and had never used anything from that category before diagnosis; "quitters" stopped using everything they had previously used in that category after diagnosis; and "never users" never used any modality within a category.

2.3.2. Statistical Analyses. First, univariate regression analyses were performed to identify the variables that were independently associated with use of self-care/practitioner-based CAM before and after diagnosis. Then, 2 sets of multivariable logistic regression models were developed to identify factors independently associated with (1) continuously using and (2) starting to use a category of modality after diagnosis [17]. Age, income, education, and stage at diagnosis as reported at the baseline interview, were selected as a priori confounders. All factors found to be statistically associated with always using CAM before and after diagnosis (with a $P$ value of $<0.05$ in at least one of the categories) were included in the full models so that the odds ratios would be comparable across all models. The independent variables tested in univariate regression models that were not included in the final multivariable models $(P>0.05)$ were oral contraceptive use, hormone replacement therapy, stage at diagnosis, and hormone receptor status. The final models were adjusted for age at diagnosis, race, income, education, body mass index (BMI, defined as weight in kilograms divided by height in meters squared), health behaviors (including mammogram within 5 years prior to diagnosis, cigarette smoking, alcohol use, physical activity, and fruit and vegetable intake) as reported at baseline, continuous use of other CAM categories, and first course of breast cancer treatment type, as reported at the follow-up interview.

\section{Results}

Among LIBCSP cases, 764 completed the full follow-up questionnaire and were included in this analysis. Differences 
between them and the 724 who did not have full followup data have been previously reported [14]. Among those included in this analysis $(n=764)$, mean age at diagnosis was 56.3 years; $94 \%$ were non-Hispanic white; $59 \%$ had an annual household income above $\$ 50,000 ; 61 \%$ had attended college; and $44.1 \%$ had never smoked cigarettes. At baseline, $36.8 \%$ ate at least 35 servings of fruits and vegetables per week, and 23.7\% exercised at least 2.7 hours a week (Table 2 ).

3.1. Use of Self-Care and Practitioner-Based CAM before and after Diagnosis. More than $95 \%$ of our study participants used self-care after diagnosis; most did so before as well. About $75 \%$ used a multi- or single vitamin, and about $40 \%$ used prayer, botanicals, or practitioner-based CAM (data not shown).

3.1.1. Continuous Users. Both before and after diagnosis, $55.5 \%$ of women used multivitamins; $57.3 \%$ used single vitamins; $35.5 \%$ used prayer, $29.2 \%$ botanicals, $21.6 \%$ special diets, and $16.6 \%$ mind-body practices. $25.4 \%$ of women used at least one practitioner-based modality both before and after diagnosis (Table 3 ).

3.1.2. Starters. $67.2 \%$ of women started some form of selfcare after diagnosis. The modalities most commonly started after diagnosis were multivitamins (20.5\%), single vitamins (19.1\%), support groups (17.4\%), other dietary supplements (12.3\%), and mind-body practices (11.6\%). $14.8 \%$ of women began using a practitioner-based modality after diagnosis. The particular modalities most commonly initiated after breast cancer diagnosis were calcium (25.3\%), vitamin E (22.6\%), green tea $(20.9 \%)$, support groups $(17.4 \%)$, vitamin C (16.5\%), low-fat diet (11.0\%), and glucosamine $(10.3 \%)$ (Table 3).

3.1.3. Quitters. $10.6 \%$ of women stopped using multivitamins after diagnosis. The most common modalities stopped after diagnosis were iron (11.9\%) and vitamin C (9.3\%). A small proportion of women (7.2\%) stopped using all practitionerbased modalities. Chiropractic, the most common everused practitioner-based modality (210 users or $27.5 \%$ ), was the modality most commonly discontinued after diagnosis (14.5\%) (Table 3).

\subsection{CAM Use and Self-Care during Adjuvant Treatment}

3.2.1. Use during Treatment. As previously reported [14], all 764 respondents who participated in the complete followup study reported undergoing surgery for their breast cancer; 310 (40.6\%) also received chemotherapy, $464(60.7 \%)$ radiation therapy, and $462(60.5 \%)$ tamoxifen treatment. The forms of self-care most frequently used during chemotherapy were prayer $(48.7 \%)$, multivitamins (37.42\%), single vitamins (33.2\%), mind-body (28.4\%), and support groups $(23.9 \%)$; $21.6 \%$ of women used practitioner-based modalities. The forms of self-care most commonly used during radiation therapy were multivitamins (55.2\%), single vitamins (48.7\%), prayer (39.9\%), mind-body (31.0\%), and special diets (29.0\%);
$17.4 \%$ of women used practitioner-based modalities. The self-care modalities most commonly used during tamoxifen treatment were multivitamins $(80.7 \%)$, prayer $(38.1 \%)$, single vitamins (23.6\%), mind-body (22.9\%), and special diets (26.0\%); $26.0 \%$ of women used practitioner-based modalities (Table 4).

\subsection{Factors Associated with Self-Care and Practitioner-Based CAM before and after Diagnosis}

3.3.1. Demographics. Higher education was a strong predictor of both starting mind-body practices after diagnosis and using such practices before and after diagnosis (continuous use); education was also associated with continuous use of botanicals and dietary supplements. Income was associated directly with continuous single vitamin use and inversely with continuous use of other dietary supplements (Table 5); income was inversely associated with beginning practitionerbased CAM after diagnosis (Table 6). Race was the demographic variable most strongly associated with starting selfcare after diagnosis; women of minority race/ethnicity were about 3.5 times as likely to start using botanicals or special diets as non-Hispanic whites (Table 6). Younger women and women with more education were more likely than older and less educated women to start using noningestible forms of self-care or practitioner-based CAM after diagnosis (Table 6).

3.3.2. Health Behaviors. Healthy behaviors reported at the baseline interview were more strongly associated with continuously using self-care than with starting self-care after a diagnosis with first primary breast cancer. Those with the highest level of physical activity ( $>2.7 \mathrm{hr} /$ week) were 2.4 times as likely to use mind-body modalities before and after diagnosis as those who reported no physical activity. Women who had a mammogram within 5 years before diagnosis were 2 times as likely to be continuous users of single vitamins as women who had not had a recent mammogram. Women whose intake of fruits and vegetables was high were $50 \%$ more likely to use multivitamins and/or botanicals continuously than those whose intake was low (Table 5).

Current smokers had $60 \%$ lower odds of following a special diet before and after diagnosis than never smokers (Table 5). Women with a body mass index (BMI) $\geq 30$ had $60 \%$ lower odds of always using other dietary supplements and women with a BMI between 25-29 had 50\% lower odds of continuously using mind-body practices than women with a $\mathrm{BMI}<25$. Women with $\mathrm{BMI} \geq 30$ were twice as likely to start mind-body practices as women with a BMI $<25$ but nearly $80 \%$ less likely to start a special diet (Table 6).

High BMI was also associated with continuous use of practitioner-based modalities $(\mathrm{OR}=2.5)$; high fruit and vegetable intake was associated with starting practitionerbased CAM after diagnosis $(\mathrm{OR}=1.8)$.

3.3.3. Continuous Use of Other Self-Care and PractitionerBased CAM. In our multivariable logistic regression models, among women with a diagnosis of first primary breast cancer, the strongest and most common predictors of continuous 


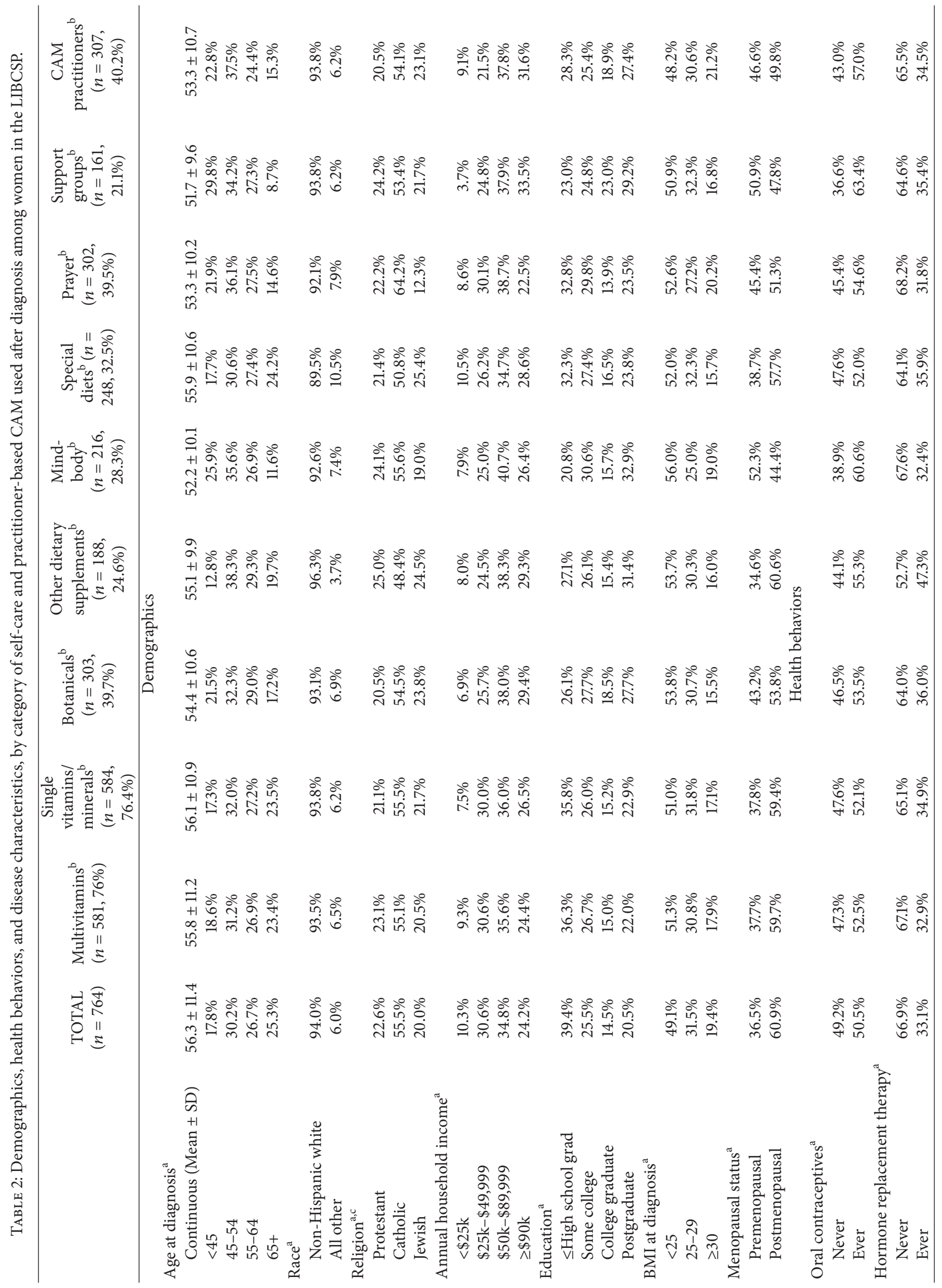




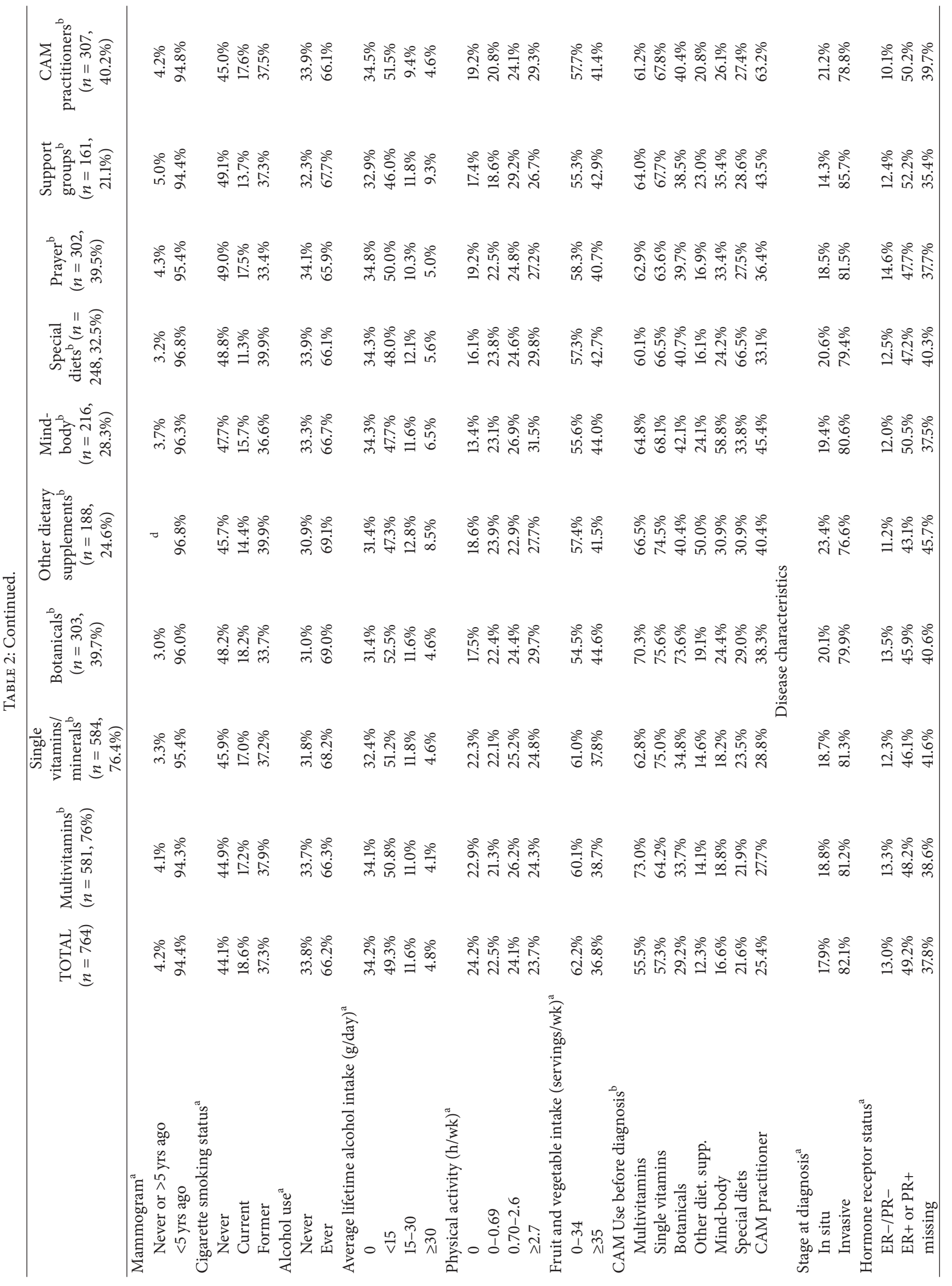




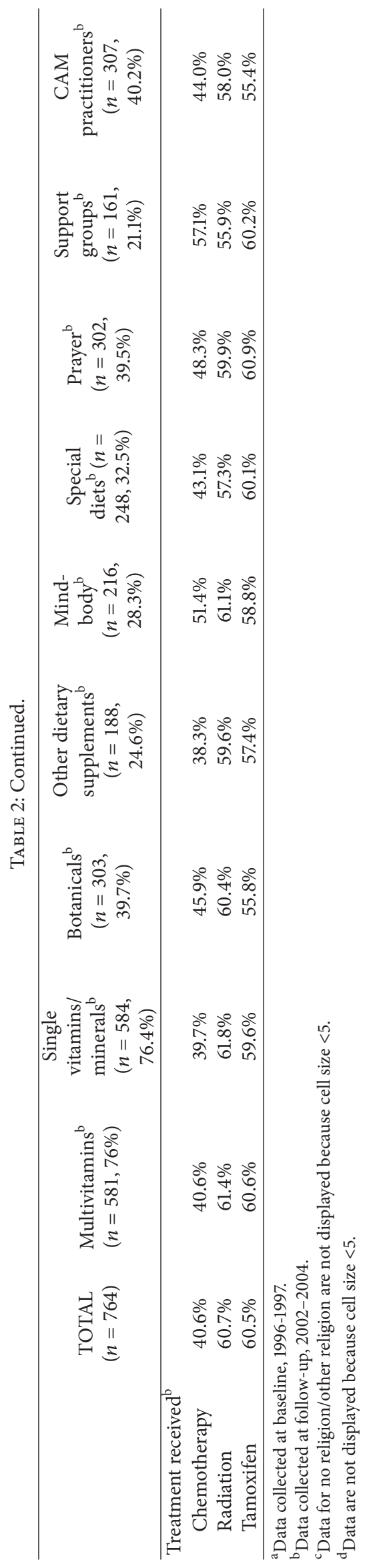


TABLE 3: Timing of the top 6 self-care and practitioner based modalities per category among women in the LIBCSP follow-up interview (2002-2004).

\begin{tabular}{|c|c|c|c|c|}
\hline & Starters & Continuers & Quitters & Never users \\
\hline Multivitamins (any) & $20.5 \%$ & $55.5 \%$ & $10.6 \%$ & $13.4 \%$ \\
\hline Single Vitamins & $19.1 \%$ & $57.3 \%$ & $5.0 \%$ & $18.6 \%$ \\
\hline Calcium & $25.3 \%$ & $20.9 \%$ & $4.1 \%$ & $49.7 \%$ \\
\hline Vitamin E & $22.6 \%$ & $24.7 \%$ & $4.2 \%$ & $48.4 \%$ \\
\hline Vitamin C & $16.5 \%$ & $32.7 \%$ & $9.3 \%$ & $41.5 \%$ \\
\hline B12 & $8.9 \%$ & $3.5 \%$ & $5.2 \%$ & $82.3 \%$ \\
\hline B Complex vitamins & $7.9 \%$ & $7.1 \%$ & $4.5 \%$ & $80.6 \%$ \\
\hline Iron & $3.7 \%$ & $2.1 \%$ & $11.9 \%$ & $82.3 \%$ \\
\hline Botanicals & $10.5 \%$ & $29.2 \%$ & $1.6 \%$ & $58.8 \%$ \\
\hline Green tea & $20.9 \%$ & $2.4 \%$ & a & $76.3 \%$ \\
\hline Echinacea & $9.8 \%$ & $4.7 \%$ & $1.2 \%$ & $84.3 \%$ \\
\hline Ginkgo biloba & $4.6 \%$ & $1.6 \%$ & $1.3 \%$ & $92.5 \%$ \\
\hline Black Cohosh & $2.1 \%$ & a & a & $97.5 \%$ \\
\hline St. John's Wort & $1.3 \%$ & a & a & $98.2 \%$ \\
\hline Chamomile & $0.7 \%$ & $1.6 \%$ & $0.0 \%$ & $97.8 \%$ \\
\hline Other OTC products & $12.3 \%$ & $12.3 \%$ & $3.0 \%$ & $72.4 \%$ \\
\hline Glucosamine & $10.3 \%$ & a & $0.7 \%$ & $88.5 \%$ \\
\hline Chondroitin & $8.8 \%$ & a & $0.9 \%$ & $89.8 \%$ \\
\hline Co-Q-10 & $8.1 \%$ & $2.0 \%$ & a & $89.4 \%$ \\
\hline Fish oil & $5.5 \%$ & $2.2 \%$ & $3.3 \%$ & $89.0 \%$ \\
\hline Fiber supplements & $4.7 \%$ & $5.0 \%$ & $3.0 \%$ & $87.3 \%$ \\
\hline Mind-body & $11.6 \%$ & $16.6 \%$ & $1.4 \%$ & $70.3 \%$ \\
\hline Visualization & $7.7 \%$ & $4.5 \%$ & $0.7 \%$ & $83.2 \%$ \\
\hline Meditation & $6.9 \%$ & $8.5 \%$ & $1.2 \%$ & $83.2 \%$ \\
\hline Yoga & $6.8 \%$ & $3.3 \%$ & $1.7 \%$ & $83.2 \%$ \\
\hline Tai chi & $3.3 \%$ & $0.7 \%$ & $1.4 \%$ & $83.2 \%$ \\
\hline Poetry & $2.6 \%$ & $3.1 \%$ & a & $83.2 \%$ \\
\hline Music therapy & $1.8 \%$ & $5.2 \%$ & $0.0 \%$ & $83.2 \%$ \\
\hline Prayer & $4.80 \%$ & $35.5 \%$ & $0.0 \%$ & $59.7 \%$ \\
\hline Support groups & $17.40 \%$ & $3.70 \%$ & $0.8 \%$ & $78.1 \%$ \\
\hline Special diets & $10.9 \%$ & $21.6 \%$ & $1.0 \%$ & $66.5 \%$ \\
\hline Low-fat diet & $11.0 \%$ & $14.9 \%$ & $1.0 \%$ & $72.1 \%$ \\
\hline Weight loss & $8.8 \%$ & $4.1 \%$ & $3.5 \%$ & $83.1 \%$ \\
\hline Change consumption of soy & $6.9 \%$ & $1.2 \%$ & a & $91.6 \%$ \\
\hline No red meat & $6.4 \%$ & $3.8 \%$ & a & $89.3 \%$ \\
\hline Organic & $5.9 \%$ & $1.4 \%$ & a & $92.5 \%$ \\
\hline High fiber & $5.1 \%$ & $3.0 \%$ & a & $91.6 \%$ \\
\hline Practitioner-based & $14.8 \%$ & $25.4 \%$ & $7.2 \%$ & $52.6 \%$ \\
\hline Massage & $9.4 \%$ & $7.6 \%$ & $0.7 \%$ & $81.9 \%$ \\
\hline Chiropractor & $6.2 \%$ & $12.0 \%$ & $8.9 \%$ & $72.5 \%$ \\
\hline Acupuncture & $6.0 \%$ & $1.4 \%$ & $2.8 \%$ & $89.7 \%$ \\
\hline Reiki, healing touch, other energy & $5.5 \%$ & $0.9 \%$ & $\mathrm{a}$ & $92.9 \%$ \\
\hline psychotherapy & $5.5 \%$ & $8.1 \%$ & $2.1 \%$ & $84.3 \%$ \\
\hline Nutritionist or dietician & $3.5 \%$ & a & $0.7 \%$ & $95.7 \%$ \\
\hline
\end{tabular}

${ }^{a}$ Data are not displayed due to cell sizes $<5$.

use of one type of self-care were continuous use of other types of self-care. In particular, users of one type of ingestible self-care were more likely to use other ingestible agents. Women who continuously used single vitamins were nearly 4 times as likely to use multivitamins and/or use other dietary supplements and 1.6 times as likely to use botanicals before and after diagnosis as other women. Similarly, women who used botanicals before and after diagnosis were nearly twice 
TABLE 4: Proportion of CAM use during treatment, by treatment type, among women in the LIBCSP follow-up interview (2002-2004).

\begin{tabular}{|c|c|c|c|}
\hline & Chemotherapy $(n=310)$ & Radiation $(n=464)$ & Tamoxifen $(n=462)$ \\
\hline Multivitamins (any) & $37.4 \%$ & $55.2 \%$ & $80.7 \%$ \\
\hline Single vitamins & $33.2 \%$ & $48.7 \%$ & $54.1 \%$ \\
\hline Vitamin E & $18.1 \%$ & $18.8 \%$ & $34.6 \%$ \\
\hline Vitamin C & $18.1 \%$ & $19.0 \%$ & $32.3 \%$ \\
\hline Calcium & $12.3 \%$ & $12.3 \%$ & $28.8 \%$ \\
\hline Selenium & $6.5 \%$ & $6.3 \%$ & $8.4 \%$ \\
\hline B-complex & $4.8 \%$ & $4.1 \%$ & $8.2 \%$ \\
\hline Herbs and botanicals & $13.2 \%$ & $12.6 \%$ & $23.6 \%$ \\
\hline Green tea & $8.1 \%$ & $4.3 \%$ & $13.6 \%$ \\
\hline Echinacea & $3.5 \%$ & $1.1 \%$ & $7.6 \%$ \\
\hline Ginkgo biloba & a & a & $3.7 \%$ \\
\hline Chamomile & a & a & $1.5 \%$ \\
\hline Garlic & a & a & $1.1 \%$ \\
\hline Black cohosh & $0.0 \%$ & $0.0 \%$ & $1.1 \%$ \\
\hline Astragalus root & $\mathrm{a}$ & a & $\mathrm{a}$ \\
\hline Other OTC Products & $8.1 \%$ & $10.0 \%$ & $16.2 \%$ \\
\hline Glucosamine & $0.0 \%$ & a & $6.3 \%$ \\
\hline Co-Q-10 & $2.3 \%$ & $2.4 \%$ & $5.6 \%$ \\
\hline Chondroitin & $0.0 \%$ & a & $5.4 \%$ \\
\hline Laxatives & $3.2 \%$ & $1.9 \%$ & $5.4 \%$ \\
\hline Flax seed oil & a & a & $3.7 \%$ \\
\hline Fish oil/EPA/Omega-3 & a & $1.5 \%$ & $3.5 \%$ \\
\hline Melatonin & a & a & $2.2 \%$ \\
\hline Mind-body & $28.4 \%$ & $31.0 \%$ & $22.9 \%$ \\
\hline Meditation & $16.1 \%$ & $12.3 \%$ & $13.0 \%$ \\
\hline Visualization & $14.5 \%$ & $9.9 \%$ & $8.0 \%$ \\
\hline Yoga & a & $1.5 \%$ & $6.9 \%$ \\
\hline Music therapy & $8.7 \%$ & $5.8 \%$ & $6.3 \%$ \\
\hline Poetry therapy or journaling & $7.1 \%$ & $3.9 \%$ & $3.7 \%$ \\
\hline Tai chi & $1.6 \%$ & a & $2.6 \%$ \\
\hline Support groups & $23.9 \%$ & $11.2 \%$ & $12.8 \%$ \\
\hline Prayer & $48.7 \%$ & $39.9 \%$ & $38.1 \%$ \\
\hline Practitioner based & $21.6 \%$ & $17.4 \%$ & $26.0 \%$ \\
\hline Chiropractor & $4.5 \%$ & $2.8 \%$ & $11.3 \%$ \\
\hline Psychotherapy & $11.3 \%$ & $5.8 \%$ & $9.1 \%$ \\
\hline Massage & $5.5 \%$ & $1.9 \%$ & $8.7 \%$ \\
\hline Reiki & $4.2 \%$ & $1.7 \%$ & $3.7 \%$ \\
\hline Acupuncture & a & a & $2.6 \%$ \\
\hline Nutritionist & $2.6 \%$ & $1.3 \%$ & $1.5 \%$ \\
\hline Special diets & $22.9 \%$ & $29.0 \%$ & $26.0 \%$ \\
\hline Low-fat & $17.4 \%$ & $15.9 \%$ & $22.1 \%$ \\
\hline No red meat & $7.4 \%$ & $6.5 \%$ & $8.0 \%$ \\
\hline Weight loss & $1.6 \%$ & $2.6 \%$ & $8.0 \%$ \\
\hline High fiber diet & $5.2 \%$ & $4.5 \%$ & $5.8 \%$ \\
\hline Organic fruits and vegetables & $6.8 \%$ & $4.7 \%$ & $4.3 \%$ \\
\hline Changed consumption of soy & $4.2 \%$ & $3.0 \%$ & $3.7 \%$ \\
\hline
\end{tabular}

${ }^{\mathrm{a}}$ Data are not displayed due to cell sizes $<5$. 


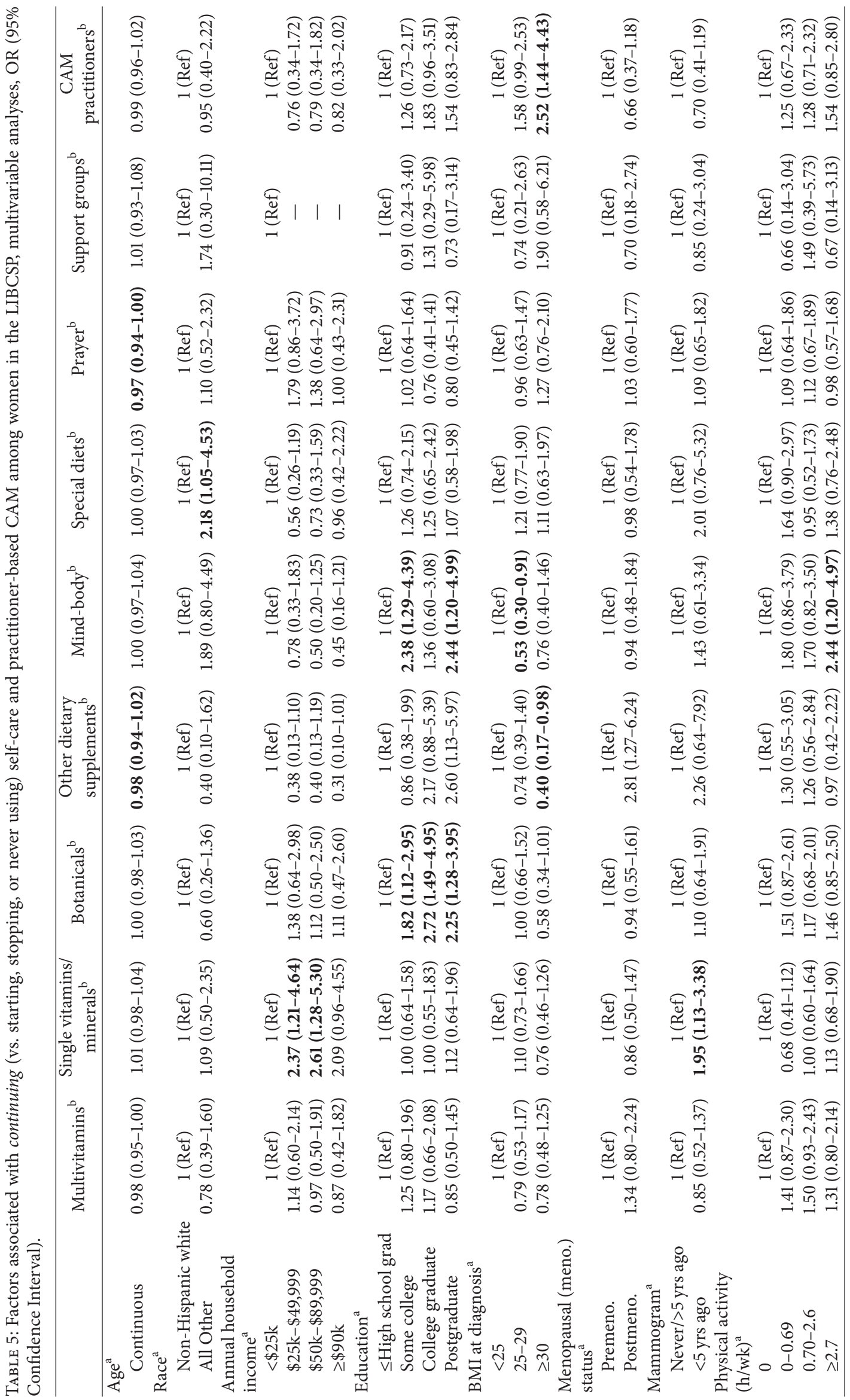




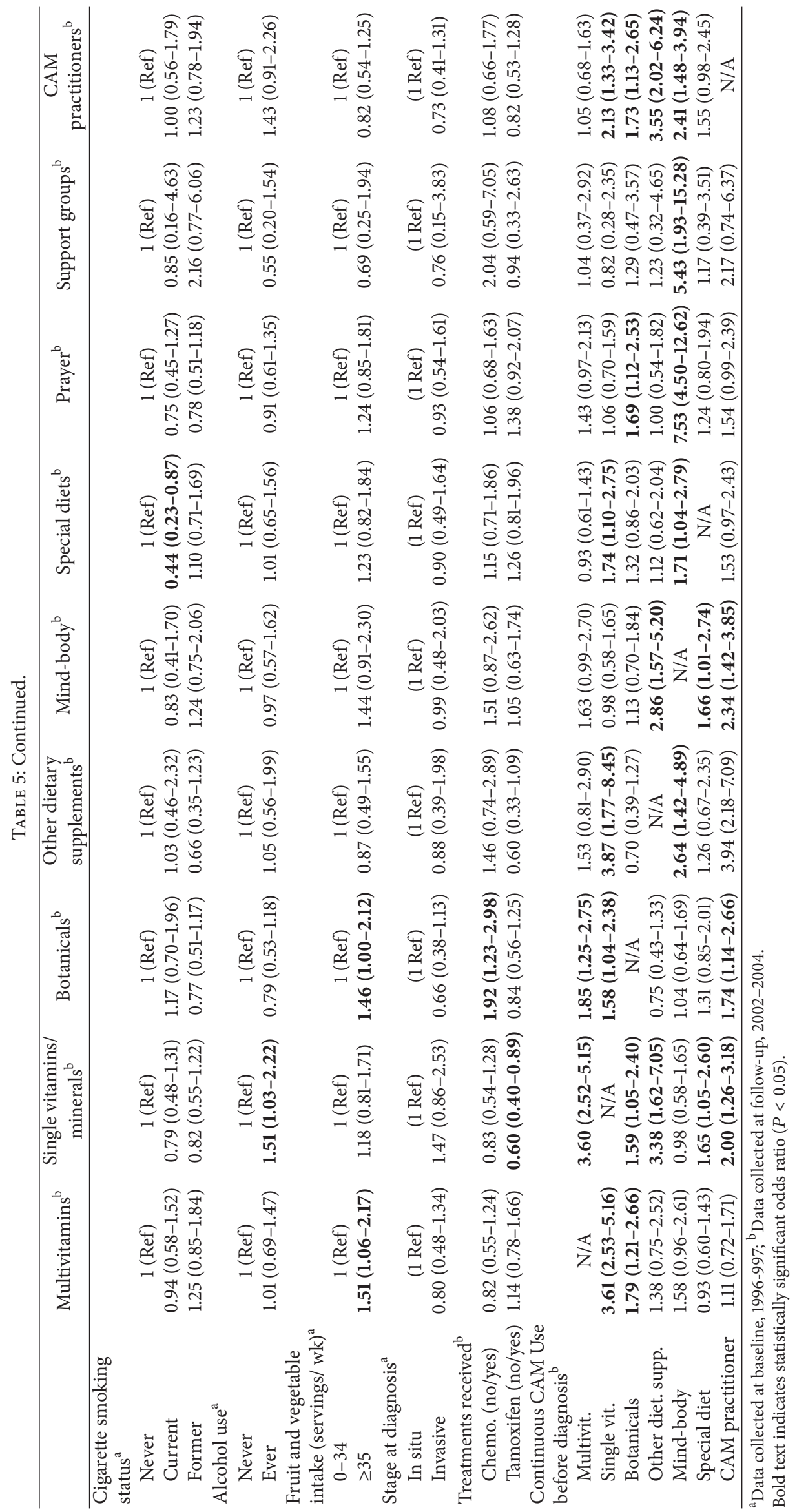




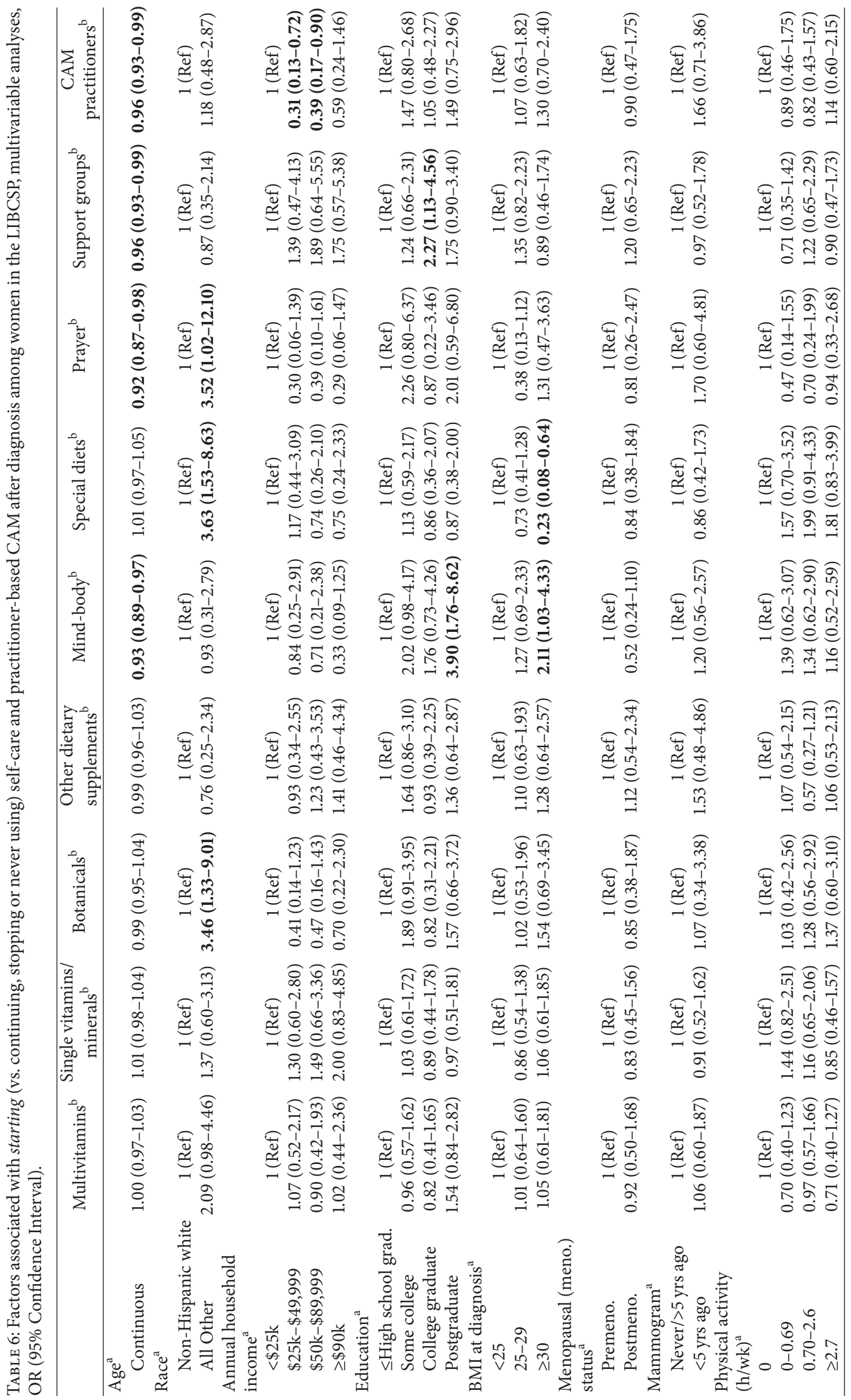




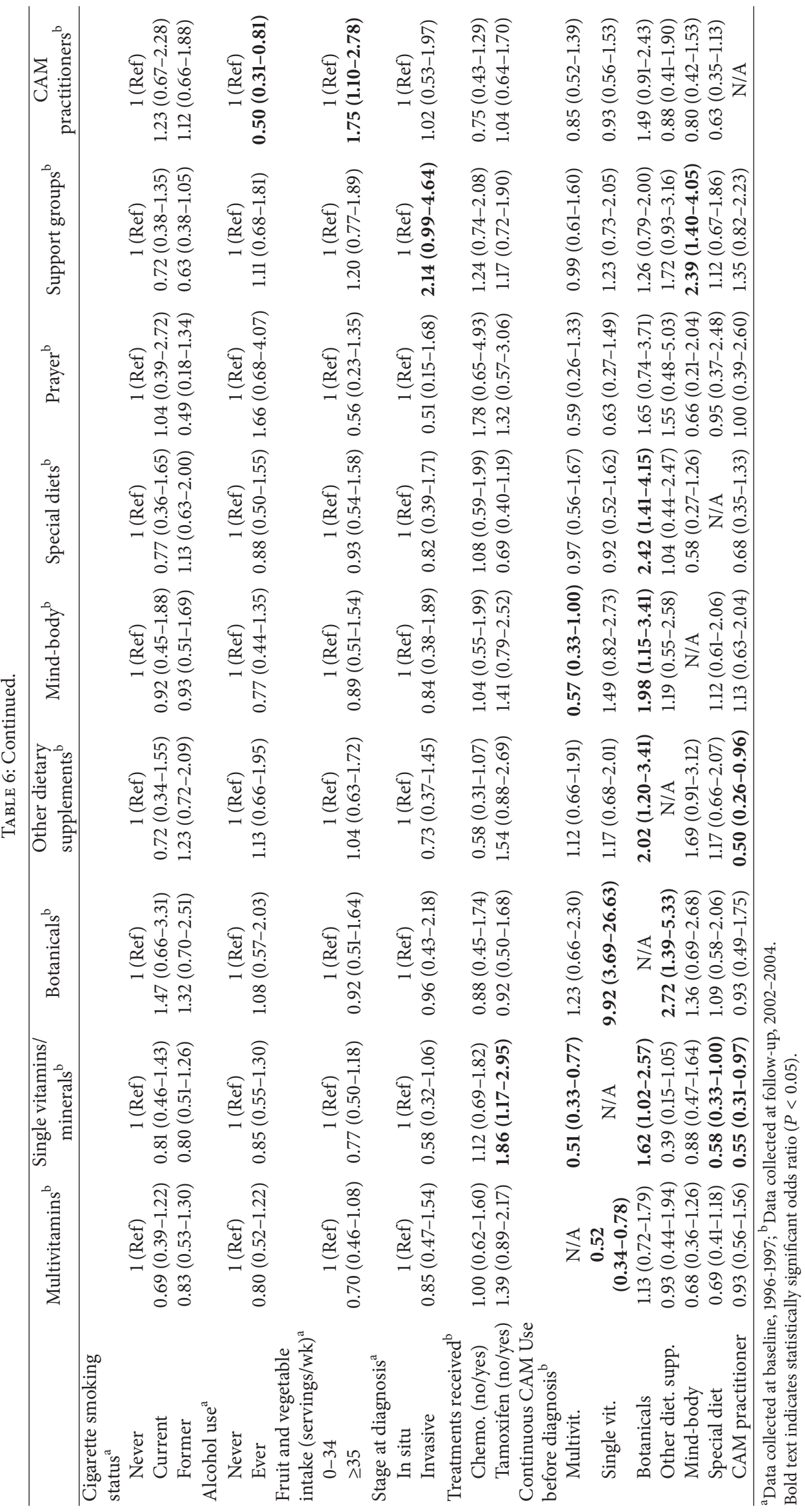


as likely to use multivitamins and single vitamins before and after diagnosis as never users of botanicals (Table 5).

Women who used ingestible forms of self-care were also more likely to begin using new categories of ingestible selfcare after diagnosis with first primary breast cancer. Women who used single vitamins before and after diagnosis were 10 times as likely to start use of botanicals after diagnosis as never users; women who used other dietary supplements before and after diagnosis were 3 times more likely to start using botanicals after diagnosis than never users (Table 6).

Continuous users of mind-body modalities were more than 7 times as likely to use prayer, 5 times as likely to use support groups, and more than twice as likely to use practitioner-based modalities continuously as non-users.

3.3.4. Disease Characteristics. Neither stage of disease nor hormone receptor status was associated with continuous or new use of self-care categories. The only clinical variable associated with self-care was treatment type: women who received tamoxifen treatment had 1.7 times greater odds of starting use of single vitamins after diagnosis than women who were not treated with tamoxifen (Table 6).

\section{Discussion}

We present a novel method to describe changes in CAM use before and after cancer diagnosis by comparing those who started using, stopped using, continued using, or never used a category of CAM following diagnosis. Cancer survivors access multiple forms of CAM and we specifically examined differences in patterns of CAM that involved "self-care" as compared to those that were based on "practitioner-care." Among women diagnosed with a first primary breast cancer who self-reported their use of complementary and alternative medicine modalities in the follow-up components of the Long Island Breast Cancer Study Project, the factors most commonly and strongly associated with using self-care and CAM modalities were use of other categories of self-care. In particular, women who used one form of ingestible self-care (multiand single vitamins, botanicals, other dietary supplements, or special diets) were more likely than other women either to continue or to start using other ingestible self-care. Healthy behaviors were associated with self-care practices that were used before diagnosis and continued afterwards. Behavioral factors were more predictive of self-care use after breast cancer diagnosis than were indicators of disease prognosis.

In a nationally representative survey conducted in 1997, which is close to the period when the LIBCSP cases were diagnosed with breast cancer, $42 \%$ of adults reported using at least 1 of 16 CAM modalities (these data did not include daily vitamins) [2]. Of those who used CAM, 46\% reported visiting a CAM practitioner within the past year [2]. The prevalence of CAM practitioner visits among the 1997 sample is comparable to that among the LIBCSP cases. Among the adults surveyed in the 2002 National Health Interview Survey, 62\% of adults reported using CAM, although this dropped to $36 \%$ when health-related prayer was excluded; natural products and breathing/meditation were the most commonly used forms of CAM [3]. 95\% of LIBCSP case women included in this analysis used self-care after breast cancer diagnosis, and $90 \%$ used self-care after diagnosis if multivitamins are excluded, which is much higher than in national samples of adults.

A recent cross-sectional study reported that $75 \%$ of adult cancer patients used CAM and of those, close to $60 \%$ began using CAM after their cancer diagnosis [18]. It has been well documented that women with breast cancer who use CAM are younger, better educated, and more affluent than women with breast cancer who do not use CAM [2, 1923]; our results are consistent with these findings. In the Women's Healthy Eating and Living Study, $81 \%$ of breast cancer survivors reported using dietary supplements [24]. In the Pathways Study, 29\% of breast cancer patients diagnosed in 2008-2009 in Northern California used special diets after diagnosis, as compared with 33\% of LIBCSP women. However, more of the participants of the Pathways Study than of the LIBCSP used botanicals (48\% versus $40 \%$ ), mind-body healing (including support groups) (64\% versus $49 \%$ ), and other dietary supplements (47\% versus $25 \%$ ) after diagnosis [9]. Differences in location and period of recruitment may account for the differences in CAM use in the two samples.

It is not surprising that the strongest predictor overall of using a self-care category before and after diagnosis with a first primary breast cancer, and of starting a self-care category after diagnosis, was using other forms of self-care. Women who already use some form of CAM or a self-care practice are likely to be aware of other CAM modalities. It is also not surprising that ingestible forms of CAM were commonly used together. Women who already take one type of supplement do not need to make much additional effort or to undergo a significant change in behavior to try new supplements. Continuous use of botanicals was the factor most commonly associated with starting new forms of self-care, including single vitamins, mind-body, other dietary supplements, and special diets. However, starting practitioner-based CAM was not associated with prior use of self-care modalities.

High intake of fruits and vegetables at the baseline interview was associated with the use of multivitamins before and after diagnosis. High recreational physical activity level reported at the baseline interview was positively associated with continuous use of mind-body practices, and high BMI at baseline was negatively associated with continuous use of botanicals, other dietary supplements, and mind-body modalities. However, healthy behaviors were not strongly associated with starting self-care practices after diagnosis; most women who engaged in healthy behaviors were already using self-care.

Neither stage of disease nor hormone receptor status was associated with starting either self-care or practitionerbased modalities. Most self-care and practitioner-based CAM use occurred during tamoxifen treatment, perhaps because tamoxifen is an oral agent that patients use for 5 years, whereas chemotherapy and radiation treatments have a usual duration of several months or weeks. In addition, women who used tamoxifen may have been more willing to use other oral or ingestible agents than women who did not use tamoxifen. Mind-body practices were also common during adjuvant treatment, perhaps because women who were told 
not to take dietary supplements during those treatments used noningestible forms of self-care instead.

The modalities that were most commonly initiated after diagnosis with breast cancer among women in our study were also the modalities most frequently used during adjuvant treatment. Although our study participants were not asked why they used the modalities they chose, data from other studies suggest that patients initiate self-care after breast cancer diagnosis due to fear or experience of treatmentrelated side effects [25-27]. A recent study that examined CAM use among breast cancer patients after adjuvant therapy similarly compared self-care (or "self-directed") CAM with "provider-directed" CAM [28]. Of those women who used self-directed CAM, over half reported using it to "influence the course of cancer after adjuvant therapy," while 95\% of women who used self-directed CAM and all women who used provider-directed CAM used it to improve wellbeing [28]. This study highlights the importance of discussing CAM use with breast cancer patients, particularly in the context of adjuvant therapy.

Among the limitations of our study, the follow-up data were collected nearly a decade ago; CAM and self-care practices may be different now. And because the data were collected more than 5 years after diagnosis and treatment, patients may not have accurately recalled their prior CAM use. Although minority race/ethnicity was associated with beginning practitioner-based CAM, only $6 \%$ of the sample were non-White, and thus the associations observed are unstable and must be interpreted with caution. In addition, although two-thirds of the case women who participated in the original LIBCSP case-control study provided some follow-up data, only $55.4 \%$ personally completed the full follow-up questionnaire, including the instrument developed by our team to assess use of CAM. We previously reported that nonrespondents to the full follow-up were of lower socioeconomic status than respondents (response bias) [14]. The well-established association of higher income with CAM use may partially explain the high prevalence of CAM use in our study population.

Growing evidence suggests that CAM and other self-care modalities may be effective in reducing treatment-related side effects, including nausea and vomiting, as well as in reducing stress and easing pain $[26,29]$. Further, engagement in selfcare practices helps individuals with cancer to maintain some sense of control over their personal wellbeing. Self-efficacy and feelings of control are predictive of improved coping, emotional wellbeing, physical health, immune function, and quality of life among cancer patients [30-33]. Henderson and Donatelle found that higher perceptions of control predicted CAM use among breast cancer patients [11]. The connection between self-care during cancer and a variety of physical and psychological outcomes should be further explored.

\section{Conclusions}

We found that a diagnosis of breast cancer was associated with subsequent behavioral changes and that more patients undertook new forms of self-care than abandoned the forms they had been using. The most popular modalities were those that are ingestible and readily available without a gatekeeper, and they were commonly used in combination. These findings are important because they identify patterns of CAM use in a well-characterized population of cancer patients, including how CAM use changed after diagnosis and during treatment. Based on research conducted to date, evidencebased guidelines are available for providers and patients about the safety and effects of various CAM modalities in the oncology setting [34-36] and can inform how and when clinicians counsel their patients on CAM use. However, more research is needed to understand the specific effects of many CAM therapies on cancer outcomes and quality of life, and further research is needed to understand the motivations for and patterns of CAM use so that a broader spectrum of patient needs can be met.

\section{Abbreviations \\ CAM: Complementary and alternative medicine LIBCSP: Long Island Breast Cancer Study Project BMI: Body mass index.}

\section{Acknowledgments}

This work was supported by contracts U01CA/ES66572, U01CA66572, and P30ES10126 from the National Cancer Institute, the National Institute for Environmental Health Sciences, and the Lance Armstrong Foundation.

\section{References}

[1] P. M. Barnes, B. Bloom, and R. L. Nahin, "Complementary and alternative medicine use among adults and children: United States, 2007," National Health Statistics Reports, no. 12, pp. 1-23, 2009.

[2] D. M. Eisenberg, R. B. Davis, S. L. Ettner et al., "Trends in alternative medicine use in the United States, 1990-1997: results of a follow-up national survey," Journal of the American Medical Association, vol. 280, no. 18, pp. 1569-1575, 1998.

[3] P. M. Barnes, E. Powell-Griner, K. McFann, and R. L. Nahin, "Complementary and alternative medicine use among adults: United States, 2002," Advance Data, no. 343, pp. 1-19, 2004.

[4] S. H. Saydah and M. S. Eberhardt, "Use of complementary and alternative medicine among adults with chronic diseases: United States 2002," Journal of Alternative and Complementary Medicine, vol. 12, no. 8, pp. 805-812, 2006.

[5] R. E. Patterson, M. L. Neuhouser, M. M. Hedderson et al., "Types of alternative medicine used by patients with breast, colon, or prostate cancer: predictors, motives, and costs," Journal of Alternative and Complementary Medicine, vol. 8, no. 4, pp. 477-485, 2002.

[6] P. A. Fasching, F. Thiel, K. Nicolaisen-Murmann et al., "Association of complementary methods with quality of life and life satisfaction in patients with gynecologic and breast malignancies," Supportive Care in Cancer, vol. 15, no. 11, pp. 1277-1284, 2007.

[7] Z. Nahleh and I. A. Tabbara, "Complementary and alternative medicine in breast cancer patients," Palliative \& Supportive Care, vol. 1, no. 3, pp. 267-273, 2003. 
[8] M. M. Lee, S. S. Lin, M. R. Wrensch, S. R. Adler, and D. Eisenberg, "Alternative therapies used by women with breast cancer in four ethnic populations," Journal of the National Cancer Institute, vol. 92, no. 1, pp. 42-47, 2000.

[9] H. Greenlee, M. L. Kwan, I. J. Ergas et al., "Complementary and alternative therapy use before and after breast cancer diagnosis: the Pathways Study," Breast Cancer Research and Treatment, vol. 117, no. 3, pp. 653-665, 2009.

[10] A. Wanchai, J. M. Armer, and B. R. Stewart, "Complementary and alternative medicine use among women with breast cancer: a systematic review," Clinical Journal of Oncology Nursing, vol. 14, no. 4, pp. E45-E55, 2010.

[11] J. W. Henderson and R. J. Donatelle, “The relationship between cancer locus of control and complementary and alternative medicine use by women diagnosed with breast cancer," PsychoOncology, vol. 12, no. 1, pp. 59-67, 2003.

[12] M. D. Gammon, A. I. Neugut, R. M. Santella et al., "The Long Island Breast Cancer Study Project: description of a multi-institutional collaboration to identify environmental risk factors for breast cancer," Breast Cancer Research and Treatment, vol. 74, no. 3, pp. 235-254, 2002.

[13] B. N. Fink, M. M. Gaudet, J. A. Britton et al., "Fruits, vegetables, and micronutrient intake in relation to breast cancer survival," Breast Cancer Research and Treatment, vol. 98, no. 2, pp. 199208, 2006.

[14] H. Greenlee, M. D. Gammon, P. E. Abrahamson et al., "Prevalence and predictors of antioxidant supplement use during breast cancer treatment: the Long Island Breast Cancer Study Project," Cancer, vol. 115, no. 14, pp. 3271-3282, 2009.

[15] L. Bernstein, B. E. Henderson, R. Hanisch, J. Sullivan-Halley, and R. K. Ross, "Physical exercise and reduced risk of breast cancer in young women," Journal of the National Cancer Institute, vol. 86, no. 18, pp. 1403-1408, 1994.

[16] G. Block, A. M. Hartman, and C. M. Dresser, "A data-based approach to diet questionnaire design and testing," American Journal of Epidemiology, vol. 124, no. 3, pp. 453-469, 1986.

[17] D. W. Hosmer and S. Lemeshow, Applied Logistic Regression, Wiley-Interscience, 2nd edition, 2000.

[18] A. Perlman, O. Lontok, M. Huhmann et al., "Prevalence and correlates of postdiagnosis initiation of complementary and alternative medicine among patients at a comprehensive cancer center," Journal of Oncology Practice, 2012.

[19] J. A. Astin, C. Reilly, C. Perkins, and W. L. Child, "Breast cancer patients' perspectives on and use of complementary and alternative medicine: a study by the Susan G. Komen Breast Cancer Foundation," Journal of the Society for Integrative Oncology, vol. 4, no. 4, pp. 157-169, 2006.

[20] H. J. Burstein, S. Gelber, E. Guadagnoli, and J. C. Weeks, "Use of alternative medicine by women with early-stage breast cancer," The New England Journal of Medicine, vol. 340, no. 22, pp. 17331739, 1999.

[21] M. A. Richardson, T. Sanders, J. L. Palmer, A. Greisinger, and S. E. Singletary, "Complementary/alternative medicine use in a comprehensive cancer center and the implications for oncology," Journal of Clinical Oncology, vol. 18, no. 13, pp. 25052514, 2000.

[22] J. A. Astin, A. Marie, K. R. Pelletier, E. Hansen, and W. L. Haskell, "A review of the incorporation of complementary and alternative medicine by mainstream physicians," Archives of Internal Medicine, vol. 158, no. 21, pp. 2303-2310, 1998.

[23] E. Crocetti, N. Crotti, A. Feltrin, P. Ponton, M. Geddes, and E. Buiatti, "The use of complementary therapies by breast cancer patients attending conventional treatment," European Journal of Cancer, vol. 34, no. 3, pp. 324-328, 1998.

[24] V. Newman, C. L. Rock, S. Faerber, S. W. Flatt, F. A. Wright, and J. P. Pierce, "Dietary supplement use by women at risk for breast cancer recurrence. The Women's Healthy Eating and Living Study Group," Journal of the American Dietetic Association, vol. 98, no. 3, pp. 285-292, 1998.

[25] P. J. Mansky and D. B. Wallerstedt, "Complementary medicine in palliative care and cancer symptom management," Cancer Journal, vol. 12, no. 5, pp. 425-431, 2006.

[26] J. Thomas, C. Beinhorn, D. Norton, M. Richardson, S.-S. Sumler, and M. Frenkel, "Managing radiation therapy side effects with complementary medicine," Journal of the Society for Integrative Oncology, vol. 8, no. 2, pp. 65-80, 2010.

[27] C. A. Lengacher, M. P. Bennett, K. E. Kip, L. Gonzalez, P. Jacobsen, and C. E. Cox, "Relief of symptoms, side effects, and psychological distress through use of complementary and alternative medicine in women with breast cancer," Oncology Nursing Forum, vol. 33, no. 1, pp. 97-104, 2006.

[28] D. N. N. Lo-Fo-Wong, A. V. Ranchor, H. C. J. M. de Haes, M. A. G. Sprangers, and I. Henselmans, "Complementary and alternative medicine use of women with breast cancer: selfhelp CAM attracts other women than guided CAM therapies," Patient Education and Counseling, vol. 89, no. 3, pp. 529-536, 2012.

[29] J. S. Jacobson, S. B. Workman, and F. Kronenberg, "Research on complementary/alternative medicine for patients with breast cancer: a review of the biomedical literature," Journal of Clinical Oncology, vol. 18, no. 3, pp. 668-683, 2000.

[30] K. Ell, R. Nishimoto, T. Morvay, J. Mantell, and M. Hamovitch, "A longitudinal analysis of psychological adaptation among survivors of cancer," Cancer, vol. 63, no. 2, pp. 406-413, 1989.

[31] K. H. Dow, B. R. Ferrell, M. R. Haberman, and L. Eaton, "The meaning of quality of life in cancer survivorship," Oncology Nursing Forum, vol. 26, no. 3, pp. 519-528, 1999.

[32] P. Gerits and B. De Brabander, "Psychosocial predictors of psychological, neurochemical and immunological symptoms of acute stress among breast cancer patients," Psychiatry Research, vol. 85, no. 1, pp. 95-103, 1999.

[33] L. Tjemsland, J. A. Søreide, R. Matre, and U. F. Malt, "Preoperative psychological variates predict immunological status in patients with operable breast cancer," Psycho-Oncology, vol. 6, no. 4, pp. 311-320, 1997.

[34] G. Deng, M. Frenkel, L. Cohen et al., "Evidence-based clinical practice guidelines for integrative oncology: complementary therapies and botanicals," Journal of the Society for Integrative Oncology, vol. 7, no. 3, pp. 85-120, 2009.

[35] B. R. Cassileth, G. E. Deng, J. E. Gomez, P. A. S. Johnstone, N. Kumar, and A. J. Vickers, "Complementary therapies and integrative oncology in lung cancer: ACCP evidence-based clinical practice guidelines," Chest, vol. 132, no. 3, supplement, pp. 340S-354S, 2007.

[36] G. E. Deng, B. R. Cassileth, L. Cohen et al., "Integrative oncology practice guidelines," Journal of the Society for Integrative Oncology, vol. 5, no. 2, pp. 65-84, 2007. 


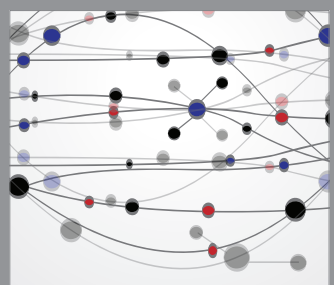

The Scientific World Journal
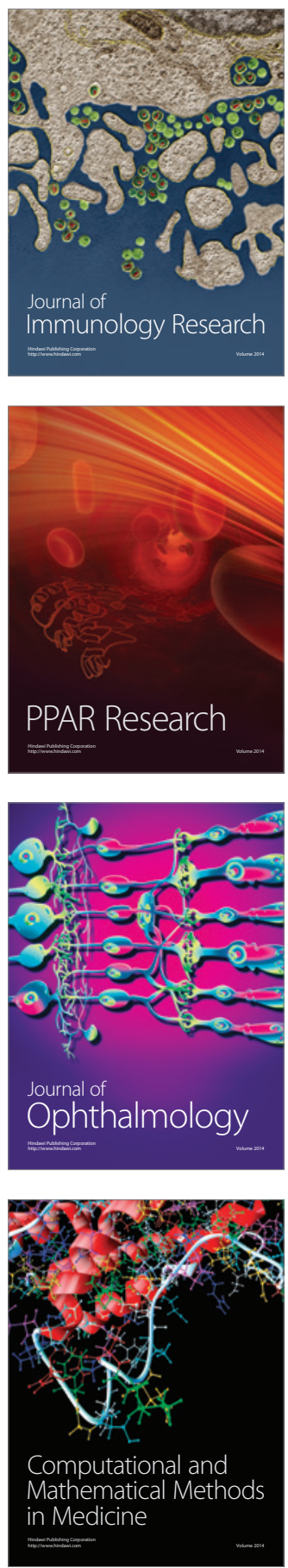

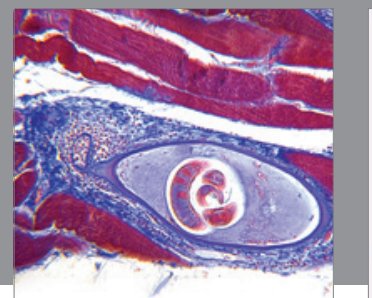

Gastroenterology

Research and Practice
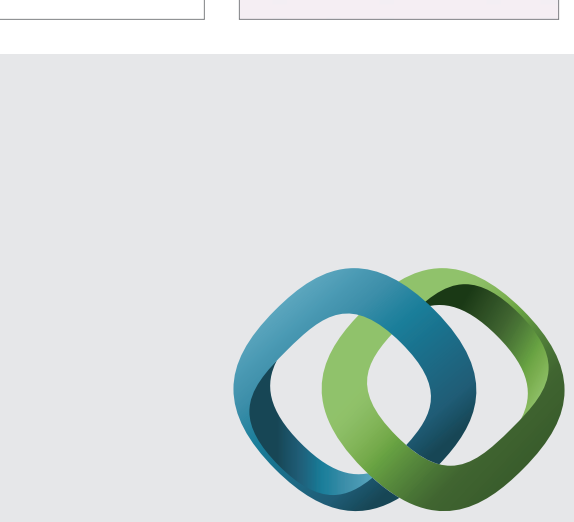

\section{Hindawi}

Submit your manuscripts at

http://www.hindawi.com
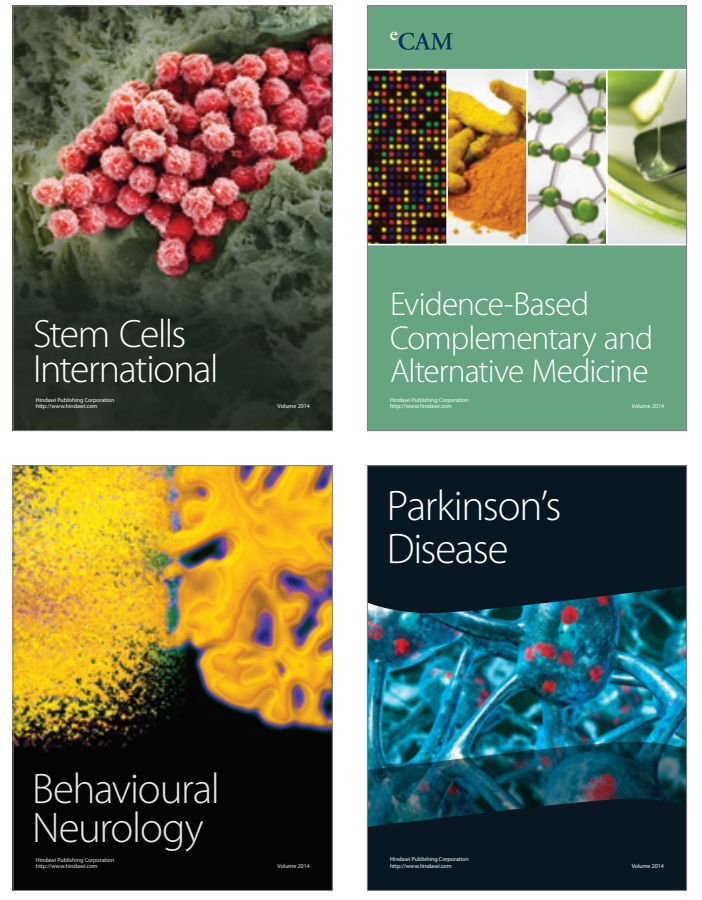
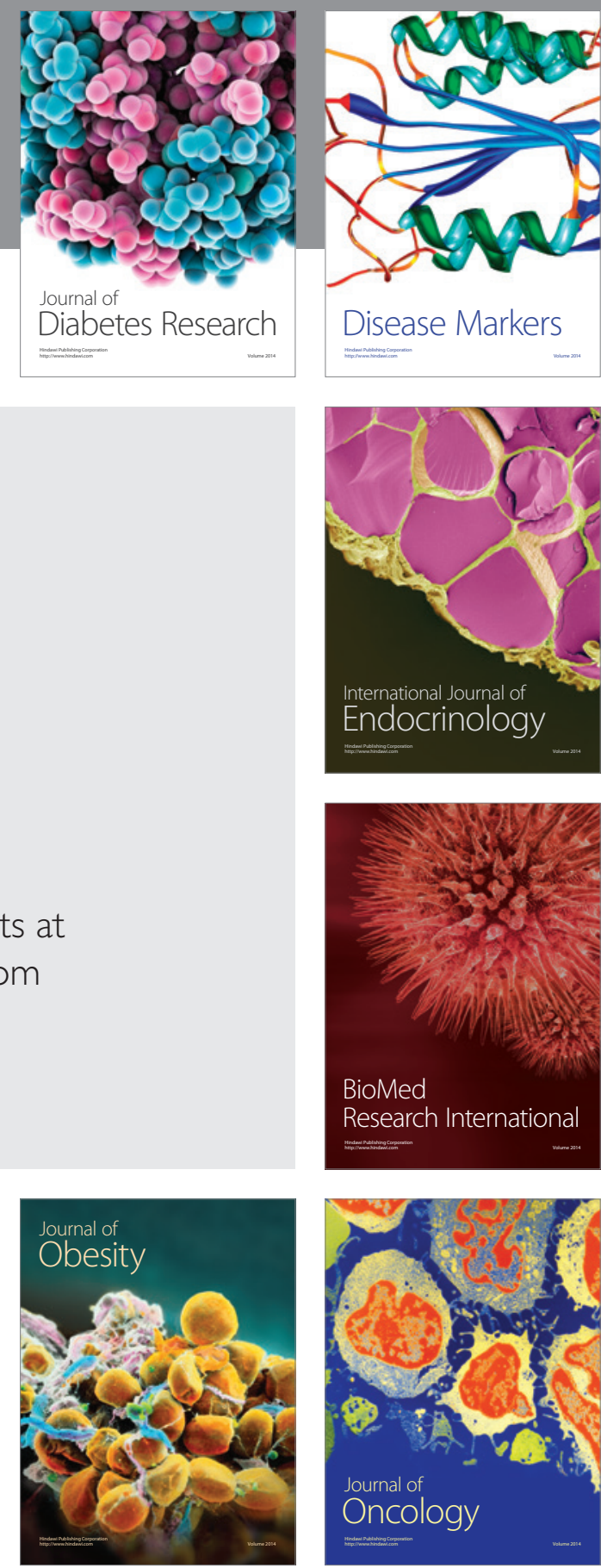

Disease Markers
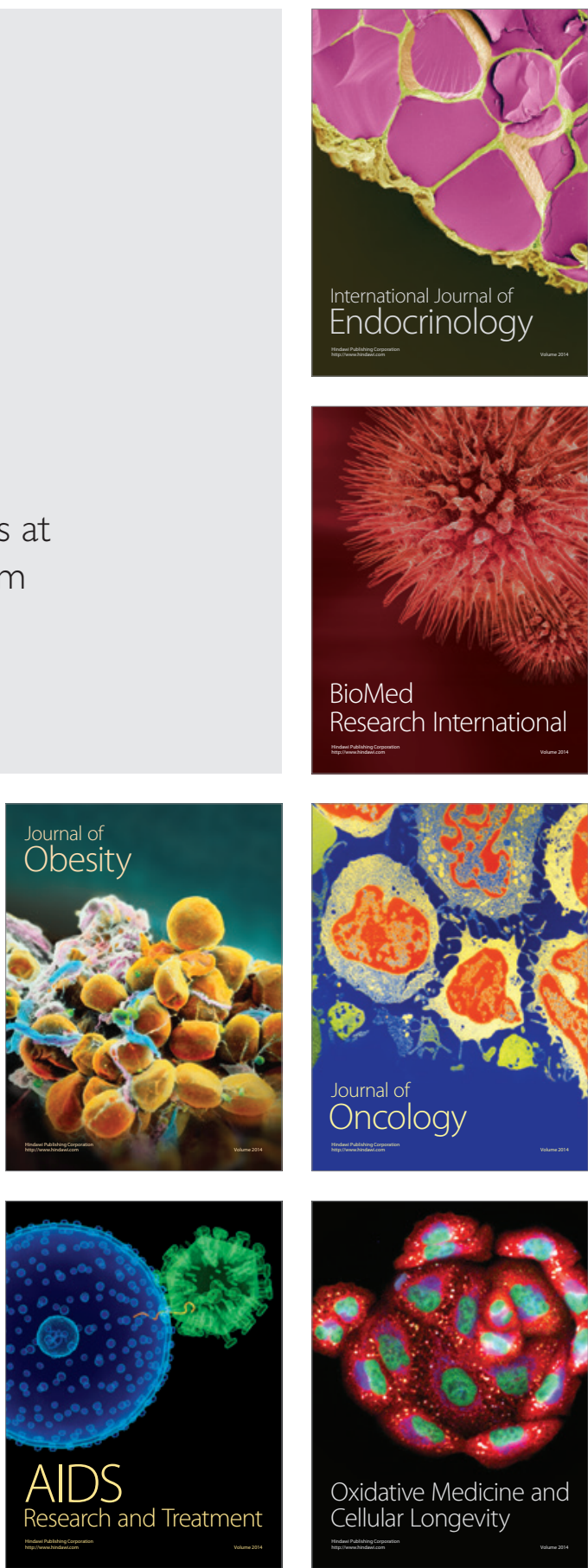